OAI-PMH: http://www.indteca.com/ojs/index.php/Revista Scientific/oai

Artículo Original / Original Article

\title{
Región Histórica y Espacio Cultural Trujillano
}

Autores: Carol Del Carmen Terán González Universidad Nacional Experimental "Rafael María Baralt", UNERMB carolteranula@gmail.com Trujillo, Venezuela Yherdyn Jacinto Peña Delgado Universidad de los Andes, ULA casahistoriatrujillo@gmail.com Trujillo, Venezuela Javier Santiago Vásquez Calderas Universidad Nacional Experimental "Rafael María Baralt", UNERMB calderavasquez@gmail.com Trujillo, Venezuela

\section{Resumen}

En procura de brindar herramientas para la comprensión de la formación del espacio cultural de la región trujillana, a través de un proceso de investigación descriptivo documental, con técnicas de recolección de datos como el uso de fichas de información para documentar el estudio y sus hallazgos, se escudriña en los cronistas de indias, y en la instauración de instituciones como el mayorazgo con el fin de sustentar el porqué de la distribución espacial y la caracterización del actual estado Trujillo como una región histórica claramente definida y sustentada en su proceso formativo, a partir del acto fundacional de la ciudad por parte de los conquistadores españoles, elementos, que se aspira a que contribuyan a la enseñanza aprendizaje de este importante proceso formativo de la identidad histórica y cultural de los trujillanos.

Palabras clave: región histórica; fundación; espacio cultural; identidad. 


\title{
Historic Region and Trujillano Cultural Space
}

\begin{abstract}
In search of offering tools for the comprehension of the formation of the cultural space of the region trujillana, across a descriptive documentary process of research, is investigated in the chroniclers of indies, and in the restoration of institutions like the primogeniture in order to sustain the why of the spatial distribution and the characterization of the current state Trujillo as a historical region clearly defined and sustained on its formative process, from the founding act of the city on the part of the Spanish conquistadors, elements, which it aims that they contribute to the education learning of this important formative process of the historical and cultural identity of the trujillanos.
\end{abstract}

Keywords: historical region; foundation; cultural space; identity. 


\section{Introducción}

Este trabajo, tiene como propósito primordial comprender la evolución del espacio regional trujillano hasta convertirse en el actual estado Trujillo, tarea impostergable en los actuales momentos, es por ello, que se recurre a los textos primarios que dan cuenta de la conquista del territorio que había sido poblado por siglos por los indígenas cuicas y que intempestivamente fue formado por los conquistadores españoles. A partir de ese momento, se inicia una reconfiguración de los referentes espaciales que había caracterizado estas latitudes hasta ese entonces. Es así, que a pesar de no pretender ocultar el pasado indígena, la fundación de la ciudad de Trujillo por parte de los españoles, es un hito que impulsa el estudio del origen de unas nuevas estructuras organizativas (ocupación, distribución, instituciones...) que formarán parte indisoluble de Trujillo como entidad política administrativa.

Pero además de ello, se entiende que el acto de fundación es sólo la chispa que origina esta conformación; por esta razón, se busca integrar otros elementos que permitan comprender el cómo y el porqué de la distribución espacial de lo que hoy es el territorio trujillano. Entonces, además de los cronistas, es necesario indagar acerca de algunas de las instituciones que surgieron con la colonia, particularmente el mayorazgo; que en Trujillo, será otorgado a la familia Cornieles y que contribuirá a darle integridad territorial a estas tierras, al jurisdiccionar amplias propiedades a lo largo y ancho del territorio, a la ciudad de Trujillo.

De esta manera, para su más clara comprensión, se recurre al estudio de una categoría altamente evasiva como lo es la región, y a partir, de un estudio documental y descriptivo, se recorrerá el devenir de esas primeras exploraciones que sentarán las bases de la estructuración así como de la diversidad y particularidad cultural de los microespacios regionales (o microrregiones culturales) que, posteriormente han estado sometidos a los vaivenes de las políticas de gobernantes que han realizado diferentes 
divisiones administrativas.

\section{Abordaje a la ciudad como génesis de la trujillanidad}

Es de recordar que el devenir de las sociedades latinoamericanas se encuentra íntimamente ligado a su propia condición de origen hispánico colonial. Es decir, que los hombres en su medio se asientan y establecen su organización en torno a las ciudades. Y a su vez, las ciudades vieron sus primeras luces con la fundación realizada por los conquistadores españoles. Con tal aseveración, bajo ningún concepto se pretende obviar o invisibilizar a las comunidades cuicas que escogieron como hogar las tierras que hoy conforman el estado Trujillo. Muy al contrario, lo que aquí se pretende, es un repaso en la evolución espacial de la territorialidad trujillana; intentando fijar los parámetros a través de los cuales la "Provincia de los Cuicas" pasó a constituirse en el actual estado Trujillo y las implicaciones de tal dinámica en la configuración del imaginario identitario de sus pobladores de ayer y hoy.

Actualmente, se busca el abordaje interdisciplinario de categorías como región, espacio, cultura, identidad; para de esta manera, reducir la mirada parcializada con la que se han fijado nuestros ojos sobre el pasado y el territorio. Lo que conduce a la construcción de una identidad fracturada, de una memoria a retazos, de una concepción espacial deformada, y más aún, incomprendida por las generaciones legatarias. Hablar de Trujillo en los momentos actuales, debiera constituir (al menos para los trujillanos) una condición propia de unidad.

Los pobladores de Trujillo, deben poseer como principal estandarte a la trujillanidad, como instrumento de afinidad; pero para ello, se debe internalizar en primera instancia el espacio físico sobre el cual se ha asentado este pueblo, sus características y las relaciones establecidas en éste entre los hombres y el espacio que los modela, los restringe y los impulsa a su transformación. Por ello, es necesario romper con muchas tradiciones que empujan a meras 
descripciones inconexas donde el espacio y el sujeto en su devenir son estudiados cada uno por su lado sin buscar la comprensión de posibles interacciones. Para generar esta ruptura, entre otras cosas, debe recurrirse a un estudio geohistórico de estas realidades; y así, ofrecer una interpretación más o menos cercana a la realidad que presentan estos contextos.

\subsection{La región: una categoría proscrita de la escuela}

El término región como categoría sociohistórica se presenta sumamente complejo, a la vez que profundamente escurridizo. Atraparlo o al menos, enmarcarlo dentro de un prisma particular se convierte en una acción difícil de acometer tanto en el acto propio de la investigación como dentro del aula de clase. Resulta evasiva en buena medida porque posee una carga polisémica que reviste cierto grado de dificultad al momento de hacer su abordaje. A este respecto, es bueno señalar con muchos investigadores en esta área que, en buena medida, "La idea de "región" es una construcción puramente intelectual, teórica. Un conjunto de elementos puede ser entendido como región según los más diversos criterios; depende enteramente del tipo de relaciones que uno decide considerar relevantes".

Es por ello, que no es de extrañar que tal aspecto no sea considerado en el quehacer escolar. Basta simplemente conformarse con una supuesta nacionalidad basada en aspectos genéricos y reduccionistas donde se difuminan las realidades locales. $\mathrm{Y}$ en la medida que se profundizan los procesos formativos se debilita la identidad y con ella se diluye el sentido de pertenencia, trayendo como consecuencia a su vez, el deterioro de la ciudadanía. A pesar de ello, es el gentilicio de la patria chica, del terruño, lo que identifica en la cotidianidad al individuo, y que de manera simultánea lo integra a sus pares con quienes comparte el espacio inmediato, pero es importante destacar que el hecho de consolidar una identidad colectiva, bajo ningún concepto implica igualdad o unidad. ¿A qué viene tal aseveración? 
Pudieran preguntarse.

Pues simplemente, es porque a pesar, de que se esté estudiando un espacio físico reducido, el mismo puede estar caracterizado por una gran diversidad que empuja a la formación de microidentidades que establecen "ghettos" culturales circunscritos a la semiótica que el sujeto construye en torno al espacio en el cual se asienta. Tal circunstancia es producto de esa condición que Medina, González, Chamorro, y Ortega (1986), señala cuando indica:

...que desde el punto de vista del espacio, la región suele asociarse a criterios muy disímiles, pues por igual se contrae a un pequeño valle fluvial, que bien se podría atrapar en una carta a escala $1: 50.000$, o a una extensa llanura que configuraría lo que Dollfus denomina una provincia geográfica, y aún a dominios espaciales y humanos mayores (pág. 29).

Como trujillanos, y vistos desde el ámbito nacional, quienes habitamos en Trujillo nos hallamos enmarcados dentro de la región andina, arrojando un velo de anonimia y uniformidad que no responde con justicia a la realidad que se vive intramuros de este espacio. Es así, que en primera instancia se debe reconocer que:

La región de los Andes cuenta con una diversidad de climas y microclimas que se relacionan con las diferencias altitudinales o pisos térmicos que caracterizan el área. La tierra caliente, templada, fría y paramera se extiende desde los 0 hasta los 5.900 metros sobre el nivel del mar y cada zona presenta un ecosistema que influyó en el desarrollo de la tecnología y las formas de organización social y política de las comunidades prehispánicas (Salazar, Rojas y Ortega, 2000, pág. 75).

Esta condición natural del espacio andino, a su vez provoca singularidades en las actividades humanas, particulariza el quehacer de los hombres y modela sustancialmente ciertos patrones y/o modelos de conducta. Conlleva a la aprehensión de además del espacio; de los signos, símbolos e 
íconos propios de la idiosincrasia de sus pobladores. Pero dicha diversidad no es una realidad exclusiva de la región andina. A lo interno de las fronteras del estado Trujillo, también se presenta tal caracterización física. Y por lo tanto, las particularidades y diversidades se hacen protagonistas en la constitución del SER trujillano. Y por ende, esa trujillanidad adquiere matices en función a las peculiaridades culturales que se han entretejido a los largo de los años en espacios que pudiéramos llamar microrregionales.

Hasta ahora, se ha indicado la existencia de microidentidades que se forman y consolidan en espacios concretos dentro de espacios más generales. Parecieran estas realidades, razón inexcusable para poder pensar, que lo que hoy constituye al estado Trujillo, dista mucho de ser considerado como una región histórica en relación dialogante con sus habitantes. Pero a pesar de esta realidad, se mostrará de manera sucinta ese complejo y extenso proceso que data tal vez a miles de años, en los que el hombre apareció en esta geografía y la hizo suya. Generando identidades que le han permitido integrarse como un todo medianamente armonioso, pero que imprime matices poli cromáticos que hablan de su riqueza cultural.

\subsection{Los orígenes}

Si bien, la región andina (y el estado Trujillo como ente constitutivo de la misma) tuvo un origen algo calamitoso, la aparición del hombre sobre estas tierras se llevó a efecto de una manera mucho más parsimoniosa. $Y$ de estos orígenes debemos partir, para poder comprender mejor la conformación identitaria del trujillano.

Es decir, romper con esa mirada restrictiva que proyecta nuestro pasado al año de 1557; ese discurso que exhibe a la presencia del europeo como acto genésico de la trujillanidad. Es así, que las primeras huellas que comienzan a dibujar lo que podría ser las bases de la futura "cartografía" trujillana provienen de los aborígenes Cuica, quienes venidos de los andes 
venezolanos (probablemente parcialidades Muiscaso Chibchas provenientes de los Andes colombianos), se asentaron en el territorio trujillano.

Y a pesar, de que estos aborígenes, no constituyeron estructuras organizativas que pudieran indicar con precisión algo similar a límites, si se extendieron por un amplio territorio donde desarrollaron sus actividades económicas y culturales y que entablaron relaciones con otras familias aborígenes lo que si modelaría un bosquejo de fronteras culturales que han utilizado a lo largo de los años los arqueólogos y antropólogos para delimitar estos grupos humanos.

Para comprender la naturaleza de este grupo humano y su posible influencia sobre el espacio, se recurre a lo expuesto por Rengifo, (2006a), que señala: "Los que habitaban el actual territorio trujillano, eran grupos sedentarios habitualmente pacíficos, que habían alcanzado un nivel de desarrollo importante por la misma condición de paz en que vivían" (Pág. 14).

El sedentarismo de éstos permitió el desarrollo de técnicas y procedimientos que condujeron a la diversificación de su actividad socioeconómica y cultural. A este respecto, se debe señalar, que queda claro que el dominio de la agricultura es el principal motor de este sedentarismo, y que tal situación de satisfacción de la necesidad primaria de alimento, devino en el desarrollo de otras actividades como la alfarería y el tejido que derivó a su vez, en la posibilidad de ocupar nuevos espacios, cuando por ejemplo lograron protección contra la inclemencia del clima. Alcanzar este tipo de desarrollo les permitió a estos indígenas adquirir ciertas particularidades, al respecto, Rengifo (2006b), indica lo siguiente:

Se distinguen entre sí por sus dialectos con los que se comunicaban, por las decoraciones de la cerámica que elaboraban para uso común y algunos de ellos, en las zonas más altas, porque las mujeres elaboraban tejidos de algodón con los que fabricaban unos sayos que usaban para cubrirse desde el pecho a las rodillas, con el fin de protegerse de los vientos y el frío... (pág. 14). 
Se ha insistido, que la historiografía predominante $u$ oficial ha ignorado por grandes períodos al mundo aborigen venezolano y trujillano, pero producto de trabajos de profesionales interesados en el asunto, se puede realizar una ubicación de estos primeros grupos humanos, ejemplo de ello, el historiador trujillano, Briceño (1982a), señala lo siguiente:

El país de los cuicas se comunicaba por el norte con los llanos de Carora y el lago de Coquivacoa, por el sur con las montañas de Mérida y los llanos de Barinas, por el este con tierras de lo que son hoy los Estados Lara y Portuguesa y por el oeste con tierras del Zulia y lago de Maracaibo, antes de Coquivacoa (pág. 58).

Pero además de esto, los indígenas Cuica establecieron parcialidades claramente definidas que dividieron este amplio territorio en localidades con una personalidad cultural bastante destacadas. Lo que a su vez, se decanta en la definición de estos espacios como núcleos formadores de identidad. Hoy, buena parte de las localidades trujillanas con "tradición" conservan su toponimia de origen claramente indígena. Recordemos, que para el acto de fundación de las ciudades por parte de los españoles, el espacio seleccionado debía reunir tres condiciones esenciales, a saber: suministro de agua, posibilidad de defensa y por último, presencia cercana de aborígenes que garantizarán o contribuyeran con la subsistencia de sus pobladores. Si se realiza un repaso somero de la ubicación de las principales parcialidades indígenas se podrá encontrar lo siguiente:

Los mucas estuvieron ubicados en lo que es hoy la capital trujillana, en el valle que riegan el río Castán y la quebrada de los Cedros; muy cerca de los mucas estaban los bombás, los sisíes o misíes, los bujayes, tonojoes, monayes y tirandaes. Estos últimos se dividían a su vez en otros grupos menores como los chachíes, chiquimbúes, mitisúes, chachiques, chacúes, marajabúes, timusúes, estivandaes, isnabuses, cajúes, isnarunes, escacoyes, curupúes y estiguates, que moraban en tierras que después pasaron a ser asiento de Pampám, San Lázaro y Santiago. En Boconó las tribus principales fueron los tostoses, niquitaos, burbusayes, 
guandaes y miquichaes. En Carache estuvo el núcleo central de los cuicas, que se acercaban a los Humocaros y comprendían varios subgrupos, entre éstos los visupites, los caraches y los chejendes. En Quebrada Grande - Distrito Urdaneta - los miquimboyes, jajoes, duríes, esnujaques, mucutíes y otros que estaban en las vecindades con los timotes. A los indios de las riberas del Momboy, en lo que fue después La Puerta, se les distinguió con el nombre de timotes. En Escuque y de allí hacia Betijoque, desde la zona baja hasta las inmediaciones del Lago de Maracaibo moraban los jirajaras, los escuqueyes, los isnotúes, los mosqueyes, los moporos, los tomoporos y los misoas, (Briceño, 1982b, pág. 76).

Tal distribución, empareja al espacio físico y al hombre, lo conduce a formas particulares de interacción y las mismas se transmiten de generación a generación. Y parece hermanarlo a un destino que lo emparenta cada día más con la tierra. Pero tal condición, será sometida a prueba, una vez que "el otro" acuda al encuentro y lo tome por asalto. Y a partir de esta confrontación se comenzará a gestar una nueva dinámica sociocultural y política económica que conducirá a la estructuración de nuevos imaginarios y de nuevas realidades.

\subsection{El encuentro}

Cuando para el año 1498, el Almirante Cristóbal Colón advierte las costas de tierra firme, el europeo aún no poseía certeza de las implicaciones de los hallazgos que se habían producido a partir del doce de octubre de 1492. Sin embargo, sin muchas reflexiones y con menos consideraciones, este expedicionario se dispuso a la exploración y la conquista del amplio territorio que reclamaba para sus monarcas.

Es así, que cuando se inicia la ocupación del occidente de Venezuela, inicialmente desde Coro y luego desde el enclave que se había constituido el pueblo del Tocuyo, medio siglo después de la llegada del español, aún no era mucho lo que se sabía al respecto de estas tierras y de los hombres que sobre 
ella realizaban su cotidianidad. Sin embargo, gracias a ciertas fuentes documentales, se puede apreciar que, desde un principio, hubo por parte de los españoles, buen interés por ocupar las tierras de los Cuicas, más que por sus posibles riquezas auríferas, por la calidad de sus suelos y la supuesta mansedumbre de sus pobladores. Éste, reunía condiciones destacadas para ser consideradas su ocupación.

Es oportuno, indicar las noticias que al respecto se poseen de los preparativos para la ocupación de la provincia de los Cuicas. Y a este respecto, el cabildo del Tocuyo delibera en torno a ello. Ramos (1992), indica lo siguiente:

...el cabildo y ciudad del Tocuyo, teniendo noticias de unas provincias de los indios Cuicas que estaban al poniente de su ciudad, a las cuales había entrado el contador Vallejo el año de mil y quinientos y cuarenta y nueve, con comisión del gobernador Tolosa, determinó enviar a descubrirlas del todo y conquistarlas (pág. 89).

De esta manera, se puede apreciar, que las tierras habitadas por los indígenas cuicas, despertaron el interés de inmediato a los nuevos hombres, venidos del otro lado del atlántico. Sin embargo, por razones no explicitadas, tardó casi una década desde el momento de la primera exploración hasta la decisión definitiva de su ocupación. Por esta razón, cuando el español, sale a la conquista, se dirige al espacio que ocupa esta laboriosa nación, lo que traerá como consecuencia, no sólo el asentamiento de la primera ciudad de los andes venezolanos, sino que además, originará tal aventura un deambular que provocará a su vez, la génesis y la germinación del asiento de la ciudad como epicentro de la dinámica social.

Para tan importante empresa, fue comisionado Diego García de Paredes, y sobre la misma, José de Oviedo y Baños nos relata a manera de crónica lo siguiente: “...salió del Tocuyo, y marchó para los Cuicas, cuya provincia atravesó siempre al Poniente, buscando sitio acomodado para poder 
poblarse, sin que en la docilidad encontrase oposición..." (Oviedo, 1967, pág. 229). Es de detallar, que el ejercicio de fundación, no fue un acto improvisado, este conquistador, se introdujo al occidente de esta comarca, hasta constatar de un sitio apto para tal fin.

En esta dinámica, mantuvo de manera incansable su marcha, “...hasta llegar a descubrir la populosa población de Escuque, situada en un lugar eminente a las vertientes del caudaloso río de Motatan [...] donde pareciéndole a Paredes paraje acomodado, por las conveniencias del sitio, fundó el mismo año de cincuenta y seis la ciudad de Trujillo..., y más allá de las discrepancias presentadas por los mismos cronistas, en lo que respecta al año de fundación y a los posteriores desplazamientos de la ciudad y sus pobladores; Trujillo estará ligado a esa relación siempre tirante entre los cuicas y el conquistador español. Por otra parte, sobre el asentamiento definitivo de la ciudad de Trujillo en el lugar que actualmente se encuentra, Urdaneta (2007), señala lo siguiente:

Se refunda la ciudad de Trujillo, por séptima vez, en el valle de los mucas, su actual asiento. "Ciudad portátil", como se la llamara, con anterioridad había sido devorada por las discordias de sus vecinos, rencillas de los fundadores, concupiscencias y maltratos a indígenas, egoísmos del gobierno actuante, y acosada por plagas de insectos (bachacos), pantanos o barriales, enfermedades diversas, truenos y temblores o tempestades, "tigres y otras sabandijas", en los diversos sitios en que anduvo fijada, como Trujillo de Cuicas, Trujillo del Collado, Trujillo de Medellín, Mirabel, Nueva Trujillo, Trujillo de Salamanca y finalmente Nuestra Señora de la Paz de Trujillo. (pág. 66).

Puede apreciarse en este relato, el agotador proceso que condujo a la consolidación definitiva de la ciudad de Trujillo, y lo que posteriormente pasaría a constituirse en la región trujillana. Pero resulta sumamente importante, detallar el cómo y los por qué de este proceso que condujo a diversos traslados de la ciudad y de sus pobladores por diferentes rincones de la nación de los 
cuicas. En este orden de ideas, Cardozo (2005a), sobre las razones que originaron la primera mudanza, expone:

Habiéndose ausentado para El Tocuyo el Maese de Campo Diego García de Paredes a rendir cuenta de la misión cumplida, sus compañeros observaron conducta injuriosa para con los escuqueños: profanaron su templo, violaron sus mujeres y se apropiaron de los bienes tribales. Esta actitud tan arbitraria hizo nacer en el indígena un sentimiento de odio hacia el español; para 1558 sobrevino un preparado ataque de los naturales que tomó de sorpresa a los españoles: quedaron estos sometidos a la tenaz "guazábara" y a un prologando sitio. Tras inenarrables días, los invasores, para no perecer, optaron por abandonar la ciudad y la comarca. La primera tentativa de conquista había fracasado (pág. 10).

Como puede apreciarse, es la conducta del español frente al indígena, lo que genera una acción armada por parte de los indígenas para expulsar al invasor español, quien con tal acción rompía la tranquilidad y hasta pudiera decirse, cierto equilibrio en la convivencia entre el habitante aborigen y este nuevo hombre venido de otras latitudes. Este será el punto de partida para el peregrinar de Trujillo y de los primeros trujillanos. Pero tal resistencia por parte de los indígenas cuicas, no pondrían fin al deseo de los españoles de conquistar y poblar estas tierras, por esta razón, en el año de 1569, una vez más se realizó un nuevo intento de repoblar la tierra de estos aborígenes, otro elemento a destacar son las disputas internas, y las dos rutas desde las cuales se pretende la conquista: la una desde el Nuevo Reino de Granada y la otra desde la provincia y gobernación de Venezuela.

Por esta razón, puede apreciarse, que la repoblación de Nueva Trujillo, no es encomendada a Diego García de Paredes (por discrepancias con el gobernador) sino, a Francisco Ruiz. Pero en esta nueva oportunidad, también se cruzaron otros europeos, los venidos del Nuevo Reino de Granada, comandados por Maldonado, situación sumamente relevante, puesto que de estas circunstancias se derivarán, no sólo los límites entre el futuro Virreinato 
y la Gobernación, si no, que en el futuro, establecerán la delimitación entre los estados Mérida y Trujillo.

Tal escenario, generó intercambio de mensajes y reuniones entre los jefes de las respectivas expediciones, algunos cronistas, exponen incluso, el estado de tensión que generó esta situación. Pero una vez afrontada, los venidos del tocuyo, tomaron iniciativa por el restablecimiento de la ciudad en el escogido inicialmente por García de Paredes. Sobre esto, Gerendas (2005a), indica:

Después de la reunión Ruiz se apresuró a enviar parte de sus hombres a reocupar el asiento de Nueva Trujillo. Él esperó unos días más, pero, viendo que Maldonado no aparecía ni ejercía ninguna acción, regresó también a esta población, iniciando de inmediato su reconstrucción. Con ello quiso aplicar la táctica de hecho consumado, anticipando un eventual regreso de Maldonado, insistiendo en sus pretensiones sobre aquellas tierras. Aquí encontró que algunas casas que había levantado García de Paredes no habían sido quemadas o destruidas por los indios, por lo que pudo aprovecharlas en la reedificación del pueblo. Para imprimir un sello personal a su gestión, le cambió el nombre a Nueva Trujillo por Mirabel, "por los estrechos vínculos que le unían con aquel pueblo de Extremadura, situada a corta distancia al norte de Cáceres. (pág. 411).

Posterior a estos sucesos, el 02 de agosto de 1559, se sucedió el nombramiento de un nuevo Gobernador (Pablo Collado) y esto condujo a su vez, a que se restaurara en su cargo al Maese Diego García de Paredes; quien en diciembre de ese mismo año emprendió viaje hacia Mirabel y como primer acto restituyó el nombre a la ciudad a Trujillo, pero esta vez la acuñó como Trujillo del Collado. Nombró cabildo y una vez más abandonó la ciudad. De esta forma, se puede entonces apreciar que los primeros cambios que se dan en la ciudad de Trujillo son en torno a su toponimia y no así, en lo referente al espacio. En esa conquista del espacio, el año de 1560 atestiguará un importante acontecimiento: la fundación de Trujillo de Salamanca en el valle 
de Boconó. Para comprender las causas que originaron este desplazamiento se recurre a lo expuesto por Gerendas (2005b), cuando señala:

La ciudad portátil permaneció en aquel sitio de Escuque un tiempo, pero debido a la insalubridad de la zona, "a causa de las grandes y ordinarias aguas y humedades con muchos truenos y rayos", como indica el padre Simón. Por lo cual decidieron salir a un lugar más sano y seguro, para el que escogieron el hermoso valle de Boconó, por sus fértiles tierras, por su clima templado debido a sus mil doscientos metros de altura sobre el nivel del mar y otras ventajosas características (pág. 425).

Autores como Arturo Cardozo (2005b, pág. 11): reseñan que es el propio García de Paredes quien traslada a Boconó la ciudad de Trujillo en el año de 1561 y argumenta como causa de tal desplazamiento, prevenir un nuevo ataque por parte de los cuicas. Mientras que Dubuc (1998, pág. 21), citando a Mario Briceño Iragorry (1990, pág. 98), indica que "Como consecuencia de estas incursiones, advirtieron un "ancho valle" de sabana limpia en las playas del Río Boconó, principio de los indios "Cuycas" y por considerar "más apacible el sitio" decidieron, en 1558, ubicar allí a Trujillo, en el cognomento de Trujillo de Salamanca.

Lo cierto del caso, es que desde el propio año de 1548, este valle, se constituye, por así decirlo, en la puerta de la nación cuica y posteriormente, en importante centro poblado, de rica agricultura y particularmente, del algodón muy apreciado por quienes habitaban en el Tocuyo para aprovecharlo en la elaboración de tejidos. A pesar de las posibles imprecisiones sobre la fecha en la que Trujillo de Salamanca fue fundada, se debe destacar que para el año de 1563, se llevó a cabo una nueva mudanza, producto de otra disputa entre los vecinos de Trujillo, la ciudad se muda nuevamente, y un reducido grupo decide quedarse en estas tierras, por lo que se ha tomado convencionalmente este año como el de su fundación; aunque Boconó como ciudad fue fundada en el 1592 por los franciscanos y nombran como patrono a San Alejo. 
Es así, que Boconó, Motatán, Sabana Larga, Pampán y Trujillo de Nuestra Señora de La Paz a parte del propio Escuque, nacieron en torno a esta dinámica de trashumancia en la que sus habitantes se vieron forzados a vivir a lo largo de trece azarosos años. Trujillo, de esta manera se va afianzando de forma paulatina con el transcurrir de los años. El territorio conquistado por los españoles será modelador de hombres de temple, laboriosos, dedicados a las actividades agrícolas y de comercio. La posesión de la tierra le va granjeando fortuna a la ciudad y a sus pobladores, los une en un sentido común. Los define como habitantes de un espacio que les pertenece y al que pertenecen.

\subsection{Las Instituciones}

La errabunda existencia de los primeros pobladores, no solo permite la exploración y la conquista de un territorio que se le arrebata a grandes tajos a los dueños originarios, sino que otorga derecho de propiedad. La administración centralizada en el cabildo de la ciudad, les permite a los habitantes que se asentaron de manera definitiva en el valle de los Mucas, hacerse de importantes propiedades, en los más diversos parajes de la geografía trujillana.

Esto permitió formar identidad, es decir ese reconocimiento del hombre con su espacio. Parte de esa construcción del Trujillo, como región histórica se afianza con una experiencia en el propio período colonial, esto es; el Mayorazgo de los Cornieles, el cual se extendió por gran parte de las tierras conquistadas y que sirvió de asiento a los primeros pobladores que se hicieron llamar trujillanos. Su condición de indivisible, garantizó de igual manera, la integridad territorial de dicho espacio, hermanando aún más al hombre con su tierra.

A este respecto, Rojo (1997a), nos señala que:

Según documento localizado en el Archivo General de la 
Nación el mayorazgo fue fundado vinculando grandes extensiones de tierra, todas ellas fraccionadas a lo largo y ancho de la jurisdicción del actual Estado Trujillo, conformando estancias de pan "llevar" y pan "coger", estancias de ganado mayor y menor (pág. 41).

Esta vinculación de tierras independientes, diseminadas por la geografía trujillana, provocan de manera indiscutida, un sentido de integración y unidad. Dicho mayorazgo se funda en fecha del 30 de junio de 1610, apenas cuarenta años después del asentamiento definitivo de la ciudad de Trujillo. Factor por el cual, se considera como instrumento que contribuye a la consolidación del estado Trujillo como región histórica. Esta distribución de tierras en beneficio de un hombre y su familia, permitirá la relación estrecha con distintas espacialidades que en otrora constituían parte de la nación cuica y que ahora se encuentra bajo el amparo del cabildo trujillano. De la misma manera, la autora antes citada, detalla lo siguiente:

El mayorazgo estaba conformado por 21 estancias de ganado mayor, que representaban cada una aproximadamente 15 cabuyas de 100 varas, más 20 varas de ancho y 29 cabuyas de 100 varas más 16 varas de largo; además de estos bienes, se incorpora a los bienes la mitad de la Sabana de la Galera, que la quebrada que la atraviesa va a dar a Misoa, pueblo de indios en la Laguna de Maracaibo, cuya extensión aproximada es de dos leguas, que vendrían a representar en hectáreas 6.210. Mas siete y un tercio de las estancias de pan llevar, que cada una de ellas, estaría conformada por 11 cabuyas más 25 varas. (Rojo, 1997b, págs. 42-43).

Y más adelante, termina indicando que;

El mayor número de estancias que conforman los bienes del mayorazgo se encuentran localizados en el cantón Trujillo, dedicados al cultivo y a la cría de ganado mayor y menor. Los llanos de Motatán ubicados en el cantón Escuque, dedicados a la cría de ganado y al cultivo de cacao. Tierras en el cantón Carache en el sitio de Agua de Obispo. Tierras en el valle de Niquitao y Boconó dedicados a la producción de trigo y a la cría 
de ganado menor y mayor en el cantón Boconó. (Rojo, 1997c, pág. 43).

Una vez más, se observa el reflejo de la cultura aborigen en la toponimia utilizada por el español, prosigue el continuo humano, se conjugan de esta manera hombre y espacio para darle sentido a un gentilicio, puesto que la intención no es agotar el tema, y tal como se les advirtió que estas líneas corresponden a un trabajo más amplio, es necesario ir redondeando algunas conclusiones derivadas de este proceso histórico.

\section{A manera de Conclusión}

Trujillo es fácilmente asumido como una región histórica debido a que su origen remonta a sus habitantes a un pasado común y compartido por las generaciones antecesoras y que asumen las generaciones legatarias. Es necesario, que en el proceso educativo estas realidades sean incluidas para su estudio y de esta manera, contribuir con la formación de la identidad. Además, resulta indispensable la creación y el uso de recursos de materiales didácticos (sobre todo cartografía histórica) que faciliten el proceso de enseñanza aprendizaje de estas realidades geográficas y culturales. De lo anterior, también se deriva la necesidad de la utilización del enfoque geohistórico para de esta manera inducir al estudio del espacio en la dinámica histórica.

Otra lección que ha quedado pospuesta es la comprensión de la diversidad espacial y cultural de la región trujillana. El estado Trujillo, es en este sentido, un crisol donde se funde la tradición, las costumbres, la memoria, en medio de diversos paisajes que los cobijan. Por último, es necesario abordar el estudio del devenir del pueblo desprendiéndose de la concepción centralista que tanto ha caracterizado la dinámica educativa. 


\section{Referencias}

Briceño, M. (1982a,b). Historia del Estado Trujillo. Trujillo, Venezuela: Imprenta del Estado.

Cardozo, A. (2005a,b). Sobre el cauce de un pueblo. Trujillo, Venezuela: Fondo Editorial Arturo Cardozo.

Dubuc, L. (1998). Proclamación de la heredad. Boconó: estancias y vivencias. Boconó, Venezuela: Anauco ediciones, C.A.

Gerendas, A. (2005). Historia de Venezuela narrada año por año 1410 1640. Revista de Pedagogía, 27(79), 353-354. Recuperado de: http://www.scielo.org.ve/scielo.php?script=sci arttext\&pid=S0798$97922006000200006 \& \operatorname{lng}=$ es\&tlng=es

Medina, A., González, J., Chamorro, D., \& Ortega J. (1986). Historia Regional. Trujillo, Venezuela: Fondo Editorial Arturo Cardozo.

Oviedo, J. (1967). Historia de la conquista y población de la provincia de Venezuela. Caracas, Venezuela: Ediciones Ariel.

Ramos, P. (1992). Noticias historiales de Venezuela. Caracas, Venezuela: Biblioteca Ayacucho.

Rengifo, D. (2006a,b). Breve historia ilustrada de Trujillo. Venezuela: Fondo Editorial Arturo Cardozo.

Rojo, Z. (1997a,b,c). El Mayorazgo de los Cornieles. Caracas, Venezuela: Academia Nacional de la Historia.

Salazar, L., Rojas, S., \& Ortega, G. (2000). Historia de Venezuela. Caracas, Venezuela: Fondo Editorial de la Universidad Pedagógica Experimental Libertador, FEDUPEL.

Urdaneta, R. (2007). Historia oculta de Venezuela (1498-2000). Carcas, Venezuela: FUNDUR Editores. 


\section{Carol Del Carmen Terán González}

e-mail: carolteranula@gmail.com

Nacida en la ciudad de Valera Edo Trujillo, Venezuela.

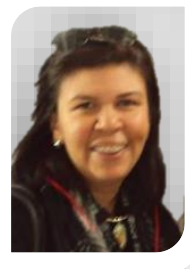

Cursó estudios de Doctorado en Educación en la

Universidad Rafael María Baralt, posee Maestría en

Docencia para la Educación Superior en la misma universidad, Maestría en Literatura Latinoamericana en la Universidad de los Andes y Licenciatura en Educación Mención Castellano y Literatura ULA-NURR investigadora del Centro de investigaciones literarias y lingüísticas Mario Briceño Iragorry. (CILL) ULANURR, jefe de la unidad de investigación y proyecto de la Casa de Historia Trujillo, articulista e investigadora con 14 años de servicio en el área de educación y literatura. Ponente en eventos nacionales e internacionales. Docente invitada en pregrado y Postgrado, ULA, UNERMB, UNESR. Coordinadora de la Línea de investigación Memoria, Educación y Discursos emergentes (UNERMB), miembro de la Línea de investigaciones Ciudadanía, hermenéutica y proyectos sociales. (UNERS). Ha realizado artículos en distintas revistas arbitradas del país. 
Yherdyn Jacinto Peña Delgado
e-mail: casahistoriatrujillo@gmail.com

Nació en Trujillo, estado Trujillo, Venezuela. Profesor de

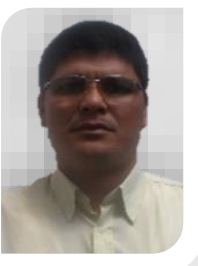
Historia del NURR - ULA. Miembro del Centro de Investigaciones Literaria y Lingüísticas "Mario Briceño Iragorry, Coordinador de La Casa de Los Tratados. Fundador - Coordinador del Taller de Historia "Abya Yala". Docente con 14 años de servicio. 


\section{Javier Santiago Vásquez Calderas}

e-mail: calderavasquez@gmail.com

Nacido en Valera estado Trujillo, Venezuela. Licenciado en Educación Integral, Maestría Orientación Mención Conducta estudiante de Doctorado En Educación Universidad Rafael María Baralt con una experiencia de 25 años en Educación, perteneciente a la Línea de investigación Memoria, educación y discursos emergentes, UNERMB. 